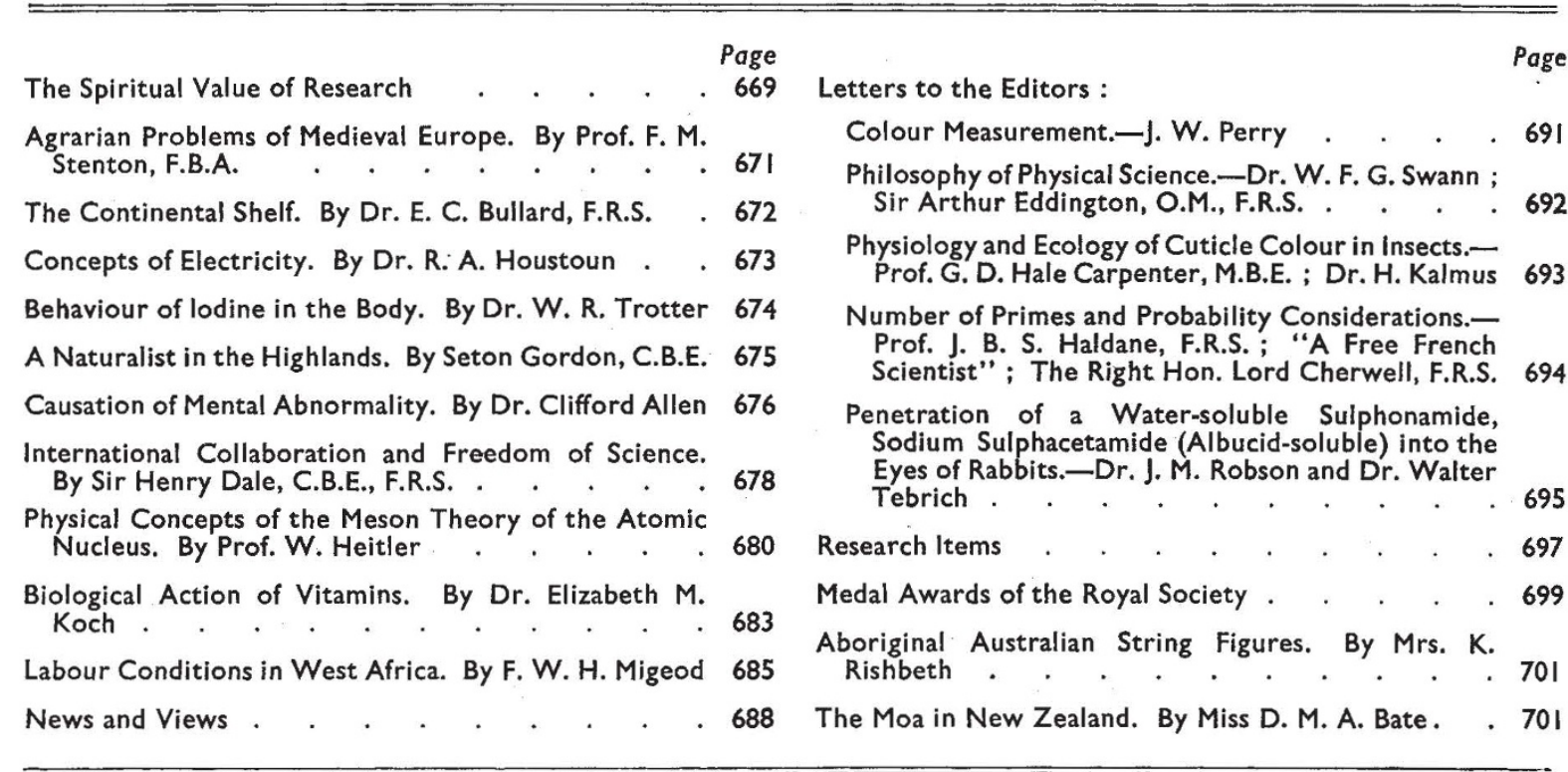

\title{
THE SPIRITUAL VALUE OF RESEARCH
}

SCIENTIFIC workers are adding here and there to human knowledge, and from time to time it is opportune to take stock in science, to ask whether the efforts are directed towards the best ends or whether we are largely chasing our own tails in working on details of established probjems.

For the purpose of this inquiry a distinction may be drawn between pure and applied scientific research, though admittedly it is improper to do so. In the first place, it is legitimate to wonder whether the best brains seek scientific work as a career. Differences in the work and in the environment of the work demand different traits of temperament and character. The level of intelligence which the honours training ensures does not necessarily mean the possession of great inventive capacity or powers of imagination. There is rather a tendency to sneer at the man engaged in utilitarian science; one sees such expressions as the greed for gain, the prostitution of science, blatant insistence on profit making. Such accusations are frankly not true; the scientific worker in industry, even if he has never published a paper in a scientific journal, can be and often is at least the equal of the academic worker.

The point is best illustrated by reference to the United States, where there are as many and as competent men of science at work in the universities and colleges as in Great Britain. In addition, most Americans will agree that there are as fine or an even finer set of brains engaged in perfecting the new discoveries and finding practical uses for them of benefit to man. Very often the practical use of something new has to be forced on man : he is told by means of advertisement that here is something that he really wants, whereupon he begins to buy it, but before long something of real value results from the development: this is happening more and more often. The chemists, for example, sought long to find a use for butyl alcohol : in the end, spray paints were discovered : not only are they of the greatest value to the motor. car industry, but also they have revolutionized the paint industry. There is nothing ignoble in making something useful, while in regard to profit, large or small, unless an article can be sold at a profit the inventor can neither live, make experiments, nor even induce anyone to undertake manufacture. President Roosevelt, speaking of a report of the National Research Council to Congress, has said it "presents a clear record of how successfully we have translated our old time Yankee ingenuity for invention into American genius for research".

Some of the facts relating to the United States are striking. Thus in $1940,2,200$ industrial corporations maintained 3,500 research laboratories 
employing 70,000 workers at a cost of seventy-five million pounds. In these, particular emphasis is directed towards personal qualities of the prospective employee as distinguished from scholarship. Creative urge, receptiveness to new ideas and intellectual integrity are particularly important. It is such men and their gifted leaders who have made the wholly synthetic textile 'Nylon', at a staggering experimental cost which it will take a long time to recover from profits. Nylon bids fair- to make the world independent of Japanese silk. In addition, all sorts of new uses, perhaps of equally outstanding value, will be found for the fibre.

Nothing which is said here indicates any desire to check pure research ; it is realized that great discoveries come only seldom and then perhaps after years of patient groundwork, also that "the wind of genius bloweth where it listeth". A difficult problem such as that of cancer must be attacked from many sides; a tiny advance here may lead to definite progress elsewhere.

There is, however, much to be gained by planning a research. In industry it is of value occasionally to review a research problem on its completion, so as to see how much time could have been saved if none but useful experiments had been undertaken : often the necessary time is but a small fraction of the time actually spent. Research expenditure is usually roughly proportional to sales: it becomes difficult to know how much money to allocate to subjects which are far in advance of the specific problems of an industry. But to-day American 'big business' men firmly believe in research and believe that they would suffer seriously were it discontinued. Chairmen produce slogans when they talk to shareholders: "The fountain of youth for a corporation is technical research which has been properly organised for profit." "Every discovery has a tremendous back. ground. . . . Every discovery in turn is a link in the chain leading to further development." "The products of to-day's researches are a base for to-morrow's orders." "The price of progress is research which alone assures the security of dividends."

Speaking of the glass industry in the United States, in which the over-riding control is exercised by one or two organizations, Prof. W. E. S. Turner has said that "so far from resting on the position acquired, they appear to be intent on strengthening the position by research development work on a considerable scale".

It must not be forgotten that many research problems are so costly nowadays that only the largest organizations can finance them. A technical research is no longer a problem for a single man with two or three helpers; it may involve a team of a hundred scientific workers and necessitate the building of a small experimental factory.

Research expenditure in such industries as food, textiles, leather, forest products has lagged behind that in the oil, rubber, chemical and electrical industries; there is, however, just as much room for it and as much reward awaiting success. Research need, indeed, should not be confined to process inventions but extended by co-operation between management and labour to fatigue, industrial psychology and related matters. To employ each worker in a way that best suits his capabilities, to enable him to perform a full day's work with a minimum of fatigue, are all desiderata which should make the strongest appeal to any well-managed firm.

Although what has been said above had direct reference to science in industry, it also applies. fundamentally in so-called pure science. As Sir Henry Dale pointed out in his presidential address to the Royal Society (p. 678), the work of the Medical Research Council and its sister bodies is evidence of the value of research under careful control exercised on behalf of the Government.

If it be accepted that no man is happy unless he works; and that the work should be worthy of the effort, then the need to ensure that each of us is enabled to do his best in congenial work is beyond question. The worker has the obligation to become fully trained, to be patient until the opportunity arises to step into his ideal post and to render service such as will justify his salary, the oncost on his job and provide something for the future development of his industry. It may take years to find out whether one has chosen a career wisely ; there may be steps to be retraced, adjustments to be made, but so long as there is a spiritual desire to make good, success, however it may be defined, can only be round the corner.

There is constant complaint about the apathy of the public towards science, its ignorance of science; but perhaps the fault is as much on the side of men of science as that of the public. In general, men of science fail to tell the public what is going on ; why, for example, margarine to-day is the equivalent in most respects of butter, whereas twenty years ago it was much inferior; the public cannot find this out for itself.

Men of science surely have a duty to the public to learn to write more simply, so as to bring home to a far larger audience than is reached at present. what science means and what it is doing. Until this can be done, no complaint of the neglect of science is justified. We may have smashed the atom and realized the alchemists' dream by the manipulation of the bits, but it does not make sense when we let the lay newspapers hint that gold from lead has become a practical possibility. 